\title{
PROGRESSIVE PATIENT CARE IN THE GERIATRIC UNIT
}

\author{
R. E. IRvine, M.D., M.R.C.P. \\ Physician, Hastings Geriatric Unit \\ From St. Helen's Hospital, Hastings
}

IT is not many years since the old-fashioned chronic wards of a hospital were thought to have an entirely custodial function. They existed to provide care and attention for elderly patients when nothing further could usefully be done.

With a rapidly ageing population this custodial approach proved inadequate, and since it was not possible to provide and staff an ever increasing number of chronic sick beds a new approach became necessary.

This was provided by the pioneers of geriatrics, Marjory Warren, Brooke, Olbrich and others who demonstrated that given proper treatment in a proper setting old people were capable of rehabilitation. They found that the majority of their patients could return to the community and thus escape the human scrap heap of the oldfashioned chronic sick ward. These pioneers and their successors have in a few years transformed geriatrics from the cinderella of the hospital service into a most active and exciting branch of medicine which has seen the development of many new ideas concerning the function of the hospital and the management of patients. One of these new ideas is progressive patient care.

\section{The Concept of Progressive Patient Care}

The idea behind progressive patient care is the classification of patients according to their medical and nursing needs. It is also a recognition of the fact that these needs change during the course of a patient's stay in hospital. In one sense the idea goes back as far as Florence Nightingale, whose practice it was to nurse the most ill patients near the entrance to the ward close to the sister's office, and to move the convalescent or least ill patients to the further end of the ward.

In geriatrics the idea really began 20 years ago when Marjory Warren (1943) made a plea that no patient should be admitted to a chronic sick ward without prior investigation in a general hospital. Following this the British Medical Association (1947) recommended the establishment of geriatric units in general hospitals. These were to be wards under consultant physicians where elderly patients could receive investigation, treatment, and rehabilitation, so that in due course they might return to the community. If they failed to respond to treatment they could be transferred later to long-stay nursing annexes. Thus was born the idea of a patient moving from one type of ward to another at the appropriate point in his illness. Later the pattern was enlarged to include the conception of a recovery home or half-way house to provide a more domestic environment away from the hospital where the patient could prepare for return to the community (Adams, 1954; King Edward's Fund, 1954). The idea was developed further by Cosin (r956, 1957) who described a scheme in which the patient was admitted to an initial treatment ward, was later transferred to a rehabilitation ward, or to an 'independent unit' for a period of selfcare if this was necessary to prepare him for discharge. A particular feature of this scheme was the conception of several long-stay annexes for different grades of patient, and the economic deployment of nursing staff was emphasized. More recently Exton-Smith (1962) has described one of the most fully developed schemes of progressive patient care so far reported from a geriatric unit. His scheme has gone further than any other in identifying and classifying patients varying needs for nursing care. Porter (1962) stressed the economic advantage of progressive patient care and claims that under this system it would be possible to build a unit of 240 beds for the same cost as 180 beds in conventional wards.

Meanwhile, in the United States, where, incidentally, the name originated, the idea of progressive patient care was evolving along a different route. Soon after the war some American hospitals introduced recovery rooms where postoperative patients could be grouped together under concentrated nursing surveillance until they regained consciousness (Leon, 1952). An extension of this idea led to the establishment of intensive care units to include acutely ill as well as postoperative patients (Haldeman and Abdellah, 1959). In American military hospitals there has 
been a long tradition of grouping critically ill patients and those capable of self-care in separate units (Claussen, I955).

There has also been an economic motive. When every patient in a hospital is provided with all the facilities for the treatment of acute illness whether he needs them or not, the costs of hospital care go up with every advance in treatment, and the whole process is wasteful of equipment and expensively trained nurses. Accordingly in 1956 the question of how to give the patient better value for money in hospital was taken up by the United States government (Golin, 1958). The results of six years research have recently been published in America and progressive patient care is now aptly described as 'the tailoring of hospital services to meet the patients' needs' and 'the right patient in the right bed with the right services at the right time' (U.S. Dept. of Health, I962).

The American classification of medical and nursing needs in progressive patient care assigns them into four groups as follows:

Intensive care. This is needed for acute and severe illness with disturbances of consciousness, respiratory failure, severe metabolic upsets, major hæmorrhage, etc. For these patients the deployment of all the most. elaborate life-saving equipment, including respirators and suction, is a necessity. Specially trained nurses are needed and the ratio of nurses to patients needs to be very high. A patient suitable for intensive care probably corresponds to the kind of patient who would be 'specialled' in this country.

Intermediate care. This is required for the majority of patients ill enough to be taken into hospital for treatment. It corresponds to the ordinary nursing care given to the 'average' hospital patient in this country. Many patients in terminal illness are also considered suitable for this grade of care.

Self-care. This is appropriate to the patient who is fully ambulant. Such patients may either be convalescent or undergoing investigation and treatment. Some patients receiving radiotherapy are suitable for this type of care.

Long-term care. This is needed for those whose stay in hospital is likely to be prolonged, either because of a need for extensive rehabilitation, or because rehabilitation is only possible to a very limited degree.

\section{Changing Needs}

Any survey of patients in a geriatric unit reveals a number of groups each requiring different types of care, not only from the point of view of their own needs, but also from the point of view of the deployment of nurses. Indeed one can hardly do better than to apply the American categories directly to geriatric patients. Only a very little modification is needed.

First there are the new patients. Most of these are acutely ill, and require the same kind of treatment as is given in any hospital to the acutely ill patient, the only difference being that they are likely to be out of bed sooner. Many will require intensive care because ill old people are often unable to make their needs known, and many are $ڤ$ confused or have other severe disturbances of 3 consciousness. The nurse has therefore to observe $\stackrel{\mathbb{Q}}{\varrho}$ them carefully and to be prepared to think for $\subseteq$ them. Moreover at the beginning of a typical $\overrightarrow{\vec{D}}$ geriatric emergency such as a severe stroke there may well be a need for oxygen, suction, intravenous fluids, catheterization, gastric intubation, and the use of electrical equipment such as the Ripple mattress. Other new patients will not be acutely ill, but will have been admitted for investigation and assessment, usually on account of some severe defect of locomotion. All such new patients will need to be in a ward where there is a high ratio of nurses to patients.

After a period devoted to assessment and the treatment of acute illness the patient's need changes. $\mathrm{He}$ is then likely to need intensive rehabilitation to get him on his feet again, or else he may need prolonged continued nursing care for what may prove to be a terminal illness. For this he needs treatment of an intermediate type in a continuation ward, where a slightly lower ratio of staff to patients will be appropriate.

If the patient's rehabilitation is started promptly he will probably find his feet again within a week or two, though with some patients it may take months before this stage is reached. Once it is reached however, the patient will be better care $\bar{\phi}$ for in a ward organized around the needs of the ambulant patient. Many such patients will still need a good deal of help with dressing and toilet, and a lot of sympathetic encouragement, but a few, usually those with no mental impairment, will be ready for a period of full self-care to prepare them for discharge. The ambulant ward and the selfcare unit fulfil one of the functions of the convalescent home used by younger patients, and can be correspondingly staffed.

A few patients will never graduate to the ambulant ward, and because of a severe residual handicap, physical or mental, but usually both, will require continued care, probably for the rest of their lives, in a long-stay nursing annexe. Ideally staff ratios here should be about the same as in the intermediate ward, but in practice are likely to be less.

\section{Identification of Needs.}

In theory it would perhaps be desirable to have wards specifically devoted to patients requiring each grade of care. In practice this cannot be fully achieved in a geriatric unit, because it is necessary to use a fixed number of beds in different types of wards to cope with a changing population of patients, and patients' needs even within a single ward may change from day to day. 
Norton, Mclaren, and Exton-Smith (1962) got over this difficulty by suggesting that patients requiring different grades of care could be identified by a colour code attached to their beds. They suggested three grades, full nursing, coloured red, partial nursing, coloured yellow, and rehabilitation, coloured blue. In the Hastings Geriatric Unit we have found this colour coding extremely valuable, but we have preferred to group the patients into four groups according to their need for care as follows:

\section{Intensive Nursing Care (Colour Blue)}

Patient to be fed and washed, and confined to bed.

Patient to be turned two-hourly day and night.

Patient to use bed-pan unless otherwise ordered.

Temperature, pulse, respiration (T.P.R.) and blood pressure to be charted as ordered.

\section{Normal Nursing Care (Colour Yellow)}

Patient to feed himself, and wash own hands and face.

Patient to use commode unless otherwise ordered.

Patient to sit out of bed as orderd by the doctor.

T.P.R. to be charted twice daily unless otherwise requested.

\section{Convalescent Nursing Care (Colour Green)}

Patient to be encouraged to help himself.

Patient to walk to toilet with assistance if necessary.

Patient should be up for at least one meal a day, and should be dressed for part of the day if possible.

Evening T.P.R. only, unless otherwise ordered.

\section{Self-Care (Colour Orange)}

No nursing attention given normally.

T.P.R. not taken unless requested.

\section{Dangerously Ill}

An additional red label is attached to the bed ends of those who are considered dangerously ill.

\section{Progressive Patient Care in a Geriatric Unit}

The Hastings Geriatric Unit serves a population of 130,000 of whom $24 \%$, about twice the national average, are of pensionable age. A special feature of the area, which is a popular one for retirement, is the large number of old peoples' homes and nursing homes. There are at least $\mathrm{I}, 000$ beds in private and charitable homes in addition to good welfare accommodation provided by the local authorities.

The Geriatric Unit has 238 beds, 138 in the main general hospital of the area, St. Helen's Hospital, and IOO away from the main hospital in three long-stay annexes. Before progressive patient care was introduced the number of patients treated per year never exceeded 600, but after it was introduced in 1959 the admissions more than doubled and in the years 1960 , 1961 and 1962 have been between 1,350 to 1,400 annually. The annual turnover is 5.9 per bed. The mortality is $35 \%$. The average age of new patients is 8o. As in every geriatric unit there is a preponderance of female beds in a proportion of five females to three male. The distribution of beds and the allocation of
TABLE I

Bed and Nurse Allocation for Progressive Patient Care

\begin{tabular}{|c|c|c|c|c|c|c|}
\hline & M. & F. & Fే & $\%$ & $\begin{array}{l}0 \\
0 \\
5 \\
\vdots \\
z\end{array}$ & 兽苞 \\
\hline $\begin{array}{l}\text { Admission unit } \ldots \\
\text { Intermediate unit .. } \\
\text { Ambulant unit } \ldots\end{array}$ & $\begin{array}{l}32 \\
10 \\
15\end{array}$ & $\begin{array}{l}23 \\
36 \\
22\end{array}$ & $\begin{array}{l}55 \\
46 \\
37\end{array}$ & $\begin{array}{l}23 \\
19 \\
16\end{array}$ & $\begin{array}{l}40 \\
29 \\
16\end{array}$ & $\begin{array}{l}\mathbf{1} / \mathbf{1} .4 \\
\mathbf{1} / \mathbf{1 . 6} \\
\mathbf{1} / \mathbf{2 . 3}\end{array}$ \\
\hline $\begin{array}{c}\text { Total in main hos- } \\
\text { pital . . . } \\
\text { Long-stay annexes }\end{array}$ & $\begin{array}{l}57 \\
32\end{array}$ & $\begin{array}{l}81 \\
68\end{array}$ & $\begin{array}{l}136 \\
100\end{array}$ & $\begin{array}{l}58 \\
42\end{array}$ & $\begin{array}{l}85 \\
50\end{array}$ & $\begin{array}{l}1 / 1.6 \\
1 / 2.0\end{array}$ \\
\hline Total & 89 & 149 & 238 & 100 & I 35 & \\
\hline
\end{tabular}

staff at each stage of progressive patient care is given in Table $\mathbf{I}$.

The figures include all grades of nurses between ward sister and nursing auxiliary. They exclude domestic assistants.

The figures include night nurses, but do not make allowances for holidays and sickness. To maintain full staffing the total number required would need to be increased by $15 \%$.

\section{Types of Patient}

The types of patient are probably typical of those accepted by any active geriatric unit.

About $70 \%$ are medical emergencies, mostly patients with heart disease, respiratory infections, urinary infections, or strokes. As there is usually no waiting list these patients are admitted immediately upon request to the geriatric house physician. Hastings has an emergency bed bureau and the Geriatric Unit takes a third of the medical emergencies referred by it.

Just under $10 \%$ are patients who are not acutely ill, but have medical and social problems that can only be dealt with in hospital. Such patients have often been seen before admission on a domiciliary visit. A few are taken in from outpatients.

Transfers from other hospital departments, mainly orthopædic, urological, and radiotherapy make up the next biggest group and comprise some $8 \%$ of admissions.

Another $7 \%$ are patients who come in as 'social admissions', either in an emergency because the person on whom they depended at home has become suddenly ill and there is no available substitute, or else for a planned period of holiday relief.

About $5 \%$ are patients with malignant disease deliberately admitted for terminal care.

At least a third of all admissions, in whichever category they come, are confused for part of their illness. Four-fifths are patients coming to the Geriatric Unit for the first time. The remainder are old patients bcing re-admitted. 


\section{The Initial-Treatment Wards}

All patients are admitted to the initial-treatment wards for assessment, which must be social as well as medical, and for treatment of their acute illness.

This arrangement enables a high concentration of medical and nursing attention, one nurse to I.4 patients, to be deployed where it is most needed. Because all new patients come to these wards the medical staff are inevitably in and out of them all day, the consultant and registrar are able to do two full rounds a week, and the Almoner pays frequent visits. These wards are centrally placed in the main hospital with easy access to the X-ray department, the Almoner's office, the medical staff office and the physiotherapy department. Every new patient has a number of routine investigations including hæmoglobin and blood urea estimations, a chest X-ray, and an ECG, and the ward staff become expert at ensuring that these important investigations are promptly carried out.

Each admission ward has a very high turnover, the highest in fact in the whole hospital, and the amount of paper work is therefore considerable. To cope with this a nursing auxiliary over and above the normal establishment has been appointed to each ward to deal exclusively with the clerical work.

These 'ward clerks' have proved themselves invaluable. They do all the documentation of new patients, and they prepare the routine pathological and $X$-ray request forms. They answer the telephone, and are responsible for seeing that the patients' old notes are obtained promptly from the records department. They book the property of new patients and of patients being transferred to other wards, and they send out letters to inform relatives that patients are being moved. They issue dangerously ill notices, and do the necessary documentation in case of death. They keep the case notes in order and file reports as they come in. They also obtain from the laboratory and X-ray department advance information over the telephone. These services cut out many delays, and lead to earlier discharge for some patients, and thus to a more efficient use of hospital beds.

The wards are equipped on the same scale as the acute medical wards, and an attempt is made, with the assistance of colour coding, to group the patients in such a way that the most ill ones are at the near end of the ward close to the sister's office. The male wards are fortunate to have male charge nurses and. staff nurses, who are expert at handling the numerous urological nursing problems which arise there.

Even in these wards for acutely ill patients there is a need for plenty of chairs, since at least four patients out of five are fit to be up in a chair for part of the day before they leave this ward.

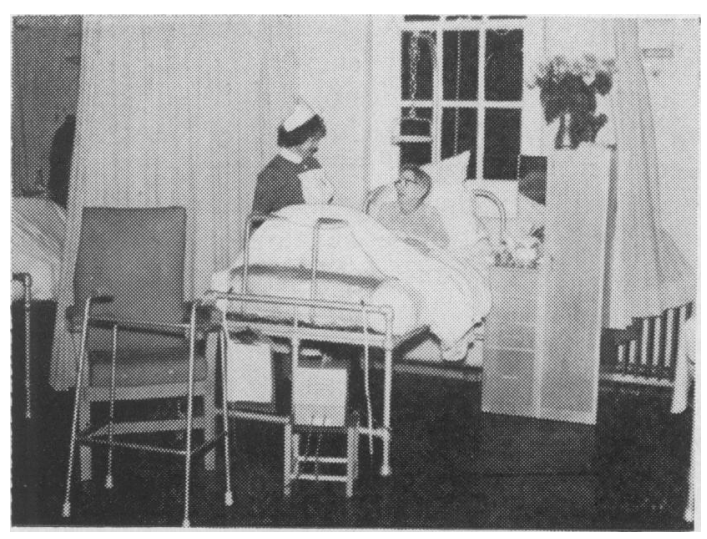

Fig. 1.-Equipment used in initial treatment ward. Note cantilever bed cradle, Ripple mattress, geriatric chair, walking aid, and bedside locker to hold the patient's clothes.

For the same reason the ward should be equipped with adjustable height beds and plentiful walking aids. In order to prevent sore heels and pressure sores every bed needs a modern type of bed cradle, and bed tables should be of the adjustable cantilever type which can be used over the bed or over an arm-chair. Because many patients will need their clothes before they leave the ward of locker suitable for this purpose is invaluable These features are shown grouped togethef in Fig. I. Full use is also made in the admission wards of mechanical nursing aids such as hoists. At present these are mostly manually operated, but doubtless the future will see more extensive use made of electrically operated hoists, of which we already have one in use.

The average stay in the initial-treatment ward is about ten days on the female side and about twice this on the male side. This is because circumstances dictate that there should be proportionately more initial-treatment beds and proportionately fewer continuation type beds on the male side. Although it is usual for the female patients to be ready to move on to the continuation ward in the course of their second week in hospital, they may be retained in the initialtreatment ward for as long as it is necessary should they continue to need intensive treatment and nursing care. A few make such rapid progress in the initial-treatment ward that they are able to go straight home from there.

\section{Transfer Procedure}

It is important to prepare the patient psychologically for the move to the intermediate ward or ambulant ward, so that it is felt to be a planned step forward in treatment and not merely a piece of gratuitous interference. The procedure is 


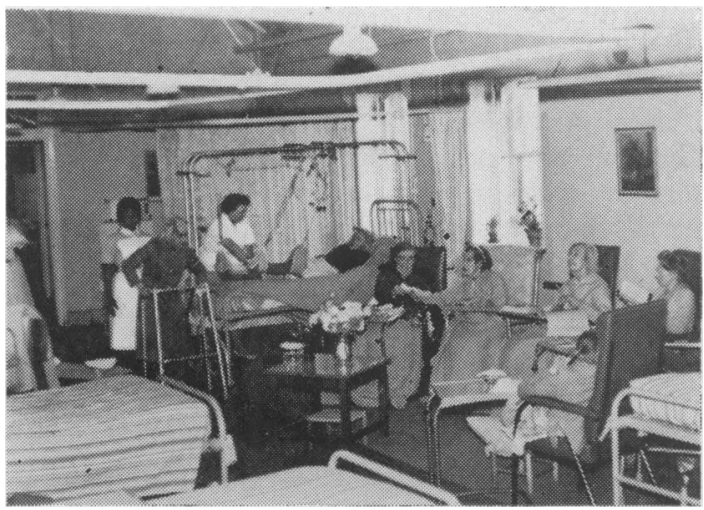

FIG. 2.-A group in the intermediate ward. Note informal arrangement of day spaces and cantilever dual purpose tables.

explained to every patient on admission to the ward (if they appear capable of understanding), and as old people are liable to be forgetful every opportunity is taken, on the doctors rounds for example, to remind them of the moves that may be in store for them.

The relatives must be informed as soon as possible what is likely to happen to the patient. A standard letter is sent to the next of kin whenever a patient is moved. We have found that contact with relatives has become easier and more informal since the introduction of open visiting in the Geriatric Unit (Irvine and Smith, 1963).

Continuity of nursing information is provided by the use of the Kardex system of nursing notes which accompany the patient wherever she goes, a most valuable innovation introduced by ExtonSmith (1962).

\section{Intermediate or Continuation Wards}

The intermediate or continuation wards have two functions, rehabilitation and continued nursing care. The primary task is to get the patients on their feet again. This task is sometimes prolonged and difficult, especially in female patients but it gives the nurses confidence to know that the patient has been fully assessed medically before transfer. They can then concentrate on their special task, to get the patient walking. Such a ward requires slightly less staff than the initial treatment ward. An establishment of one nurse to 1.6 patients proves adequate in practice.

Physiotherapy takes place on the ward since nothing does more to give a feeling of interest and life to the patients and staff.

While an attempt must be made to rehabilitate every patient it becomes obvious in some cases that this is not possible and a more traditional and less strenuous type of nursing care is then appro- priate. It is convenient to have these two types of patient, the rehabilitation patient and the continued nursing patient in one ward since there is always a good deal of interchange between the two groups and a patient who was doing well in the rehabilitation section one week may have become a candidate for terminal care the next and vice versa. By a fortunate quirk of Victorian architecture our female intermediate ward is sub-divided into six small sub-units, so patients can readily be grouped in different sections of the ward as well as being identified by the colour code.

In the intermediate ward there is no day room but the beds are arranged so as to leave a number of day spaces where the patients can gather their chairs in little groups for conversation, occupational therapy and physiotherapy (Fig. 2).

The equipment needed in the intermediate ward gives greater emphasis on rehabilitation. Handrails, Guthrie Smith frames, walking aids and tripods must be plentiful and there must be a good number of adjustable height beds. Every patient must have a geriatric chair, and these must be of a variety of types, for no one chair can suit every patient. In general, geriatric chairs should have a seat higher than the average arm-chair (about 18 in.) and a high back with a good lumbar support. Chairs for frailer patients are the better for having built-in adjustable trays. (The whole subject of chair design has been discussed by Norton, McLaren, and Exton-Smith 1962). There must also be a good supply of commodes. The types that take a bed pan are probably the best since most wards already have bed pan washers installed. Lockers to hold the patients clothes become increasingly important in an intermediate ward, since it is of the essence of rehabilitation that the patient should be dressed for a good part of the day. For many patients, especially those with stiff hips, a raised toilet seat is an advantage.

The average stay in the intermediate ward is three weeks, but if the patient is doing well a week or ten days may be all that is necessary to prepare for the ambulant ward. In other cases the period may be much more prolonged. Patients who make exceptional progress in the initialtreatment ward may be able to bypass the intermediate stage altogether and proceed straight to the ambulant ward. Some patients who do well in the intermediate ward are able to be discharged from there, if home circumstances are suitable.

\section{The Ambulant Wards}

Once the patients have graduated to the ambulant wards they are expected to be up and dressed all day, and to spend their time in the day room. The ward is thinly staffed, with only one nurse to 2.3 patients. (In practice this means 
that only two or three nurses are on duty at any one time, and only one at night.) It is equipped with low beds, so that patients can get in and out without assistance. If patients become ill, however, and require bedside nursing they must be removed straightaway, since the ambulant ward is neither staffed nor equipped to cope with such problems.

When all the patients must be up and dressed it is essential to provide facilities for their day clothes. The ordinary hospital bedside locker is not suited to this purpose and after some enquiry and experiment a satisfactory solution has been found in the form of a specially designed 'twin set'. This is based on a design originally made for Amberstone, a unit of Hellingly Mental Hospital, and has been modified for use in geriatric wards. The St. Helen's-Amberstone locker is only 2 feet wide, yet it contains a wardrobe, a chest of drawers and a mirror. The top of the chest of drawers is at a convenient height to serve as a bedside table.

This locker has proved as serviceable in the initial treatment wards as it has done in those devoted to rehabilitation, and it is proposed to introduce it by degrees as a general purpose locker throughout the geriatric unit (Fig. I).

The ambulant ward gives the patients good practice in the use of their legs, and in the more elementary activities of daily living. Group exercises are held in the ward daily, and special importance is attached to practice in climbing stairs.

\section{The Self-Care Unit}

A section of four beds in the female ambulant ward has been set aside as a self-care unit. This unit has its own small dormitory, day room, bathroom, toilet and kitchen. In the kitchen the midday meal is prepared each day by the patients under the supervision of an occupational therapist. The kitchen provides a sense of pleasure and usefulness to those who work in it and the occupational therapist finds it a convenient means of assessment for those who will have to cook for themselves after discharge. In the self-care unit the patients are expected to make their own beds and to help with the cleaning, washing up and table-laying. No nursing attention is provided at night. Commodes are not allowed, and the patient must be able to attend to her own toilet needs. It has proved a useful means of preparation for discharge, especially for those who after they go home will be living on their own, and it is as reassuring to the relatives as it is to the patients.

The male patients also have an ambulant ward but in an effort to make their life more interesting it has been arranged for them to take their midday meal in the same dining room as the women patients. Once a week a party and dance is held by the occupational thcrapists in the ambulant wards. All this social activity helps to make the patient more alert mentally and physically, and is designed to give him a greater sense of his own value and usefulness as a person. The general improvement in morale which follows is of unquestionable value in preparing the way for the patient's discharge and for his return to the community.

\section{Long-Stay Annexes}

The longer-stay patients are cared for in three nursing annexes, totalling 100 beds. The nursing establishments in these various units vary a little, but on paper are not less than one nurse to two patients. In practice the staffs are usually somewhat below strength.

One annexe, of eight beds, is in a ward in the infectious diseases hospital. This is kept for patients over 90 who need a very gentle type of care.

Another, of 26 beds, is in an old private home for invalids. This serves a dual purpose. It is principally a unit for frail ambulant patients whom it tries to bring up to the standard required for life in an old people's home which it somewhat resembles. It also undertakes some long-stay nursing care.

The main long-stay annexe, of 64 beds, is situated 8 miles away from the centre, at Battle. This is useful for those whose homes are in that area of East Sussex, but it is less convenient for those whose homes are in Hastings.

Although the long-stay annexes comprise $40 \%$ of the beds in the geriatric unit it is important to emphasize that they take less than $10 \%$ of the patients originally admitted to the Unit. An analysis of a typical years work shows that only $3 \%$ of those who come to the Geriatric Unit are still in hospital a year later, and $92 \%$ are discharged within three months.

It is important not to regard the occupants of a long-stay annexe as the poor relations of the geriatric population, and they should be kept under constant review since their medical or social circumstances may change and so allow a discharge that at one time appeared impossible. Occupational therapy is particularly important since nothing does so much, even in the feeblest patients, to preserve their morale and their sense of uniqueness as human beings. It is also important to try and arrange the admission of patients to a long-stay annexe in such a way that a trickle of discharges can take place from time to time. An occasional discharge from such a unit does a lot to improve the atmosphere.

\section{Discussion}

The pattern of progressive patient care which has evolved in Hastings is very similar to that described by Cosin (1956) and by Exton-Smith (r962), and their contention that this is a good

政


way to organize a geriatric unit can certainly be confirmed. There is no doubt that progressive patient care does, as the Americans claim, enable the nursing and medical attention offered to the patient to be varied according to his changing needs, and it has doubled the geriatric turnover.

One might think that so many moves would be upsetting to an old person, and so indeed they are at times, but only for a short while. It is not uncommon for patients to be a little confused for a day or two after a move, but thereafter they flourish in their new and more appropriate environment. They sense that each move has a purpose, and it is not difficult to help them to feel it as a step forward in treatment.

Progressive patient care is helpful to the nurses, because the frequent changes of patients from ward to ward prevent any sense of stagnation which might beset a geriatric ward. It is also a good thing to prevent a patient with a prospect of discharge from lingering too long in any one ward; for it is possible for the nurses to become too attached to such a patient, and this leads them into unconscious opposition to the idea of his discharge.

Progressive patient care is certainly helpful to the medical staff. It leads to a concentration of medical energy where it is most needed, and it also enables the doctor to change his way of looking at patients as they progress. In the admission ward the important thing is medical assessment in the traditional academic sense, but as the patient progresses further down the line functional and psychological assessment become of greater importance, and under a system of progressive patient care it is easier for the doctor to be thinking in the right terms at the right moment.

The pattern of progressive patient care that has been described is not the only one possible for a geriatric unit, and its form is largely determined by local circumstances. As compared with
Exton-Smith's (1962) scheme Hastings has a considerably larger admission section, a smaller intermediate section, and a large proportion of beds in peripheral long-stay annexes, where nursing recruitment is always difficult.

We seem to have about the right number of beds for each of the four categories of progressive patient care, but they are not ideally sited, since too many are away from the general hospital. Exton-Smith (1962) claims that two-thirds of the beds in a geriatric unit should be within the general hospital, but there is much to be said for having an even greater proportion than this at the centre, at least in urban districts. McKeown's (1958) plan for a balanced hospital community incorporating amongst other things the entire geriatric unit within the curtilage of the general hospital is probably the ideal. Nurse recruitment would be easier because of the greater variety of work, and, as the Lancet (I96r) pointed out, it would break down the artificial distinction between acute and chronic illness, and it would raise the standard of the care of the aged to a level commensurate with their needs. It would also provide the ideal setting for the practice of progressive patient care.

\section{Summary}

The concept of progressive patient care and its application to a geriatric unit is described.

Progressive patient care provides a satisfactory method of meeting the varying needs of the patient at various stages of his illness, and it leads to a more efficient use of hospital beds, medical staff, and nursing resources.

It is a pleasure to acknowledge my indebtedness to the Matron of St. Helen's Hospital, Miss B. J. Smith, the Administrator, Mr. H. Hoyle, the Head Almoner, Miss M. K. Bagnall, and to all my colleagues-medical, ancillary, nursing and clerical-in the Hastings Geriatric Unit, who have made the scheme work.

The photographs are reproduced by courtesy of $\mathrm{Mr}$. D. E. Valentine.

\section{REFERENCES}

ADAMs, G. F. (1954): Betwixt and Between, Lancet, ii, 486.

British Medical Association (1947): 'The Care and Treatment of the Elderly and Infirm'. London.

Claussen, E. (1955): Categorization of Patients According to Nursing Care Needs, Milit. Med., 1r6, 209.

Cosin, L. Z. (1956): A New Approach to the Problem of Geriatric Care, Kaiser Fdn. med. Bull., 4, 321.

(1957): 'Progress in Psychotherapy', p. I ro. New York: Grune and Stratton.

Editorial (1961): The Birmingham Venture, Lancet, i, 1212.

Exton-Smith, A. N. (1962): Progressive Patient Care in Geriatrics, Lancet, i, 260.

Golin, M. (1958): At Last a Hospital to Fit Doctor-Patient Needs, $\mathcal{F}$. Amer. med. Ass., r66, 2 180.

Haldeman, J. C., and Abdellah, F. G. (1959): Concepts of Progressive Patient Care, Hospitals, $33,38$.

IRvine, R. E., and SMITH, B. J. (I963): Patterns of Visiting, Lancet, i, 597.

King Edward's Hospital Fund (1954): 'Recovery Homes'. London.

LeON, A. (1952): Post-anæsthetic and Post-operative Recovery Units, Amer. F. Nurs., 52, 430.

McKeown, T. (1958): A Balanced Hospital Community, Lancet, i, 701.

Norton, D., McLAren, R., and Exton-Smith, A. N. (1962): 'Geriatric Nursing Problems in Hospital'. London: The National Corporation for the Care of Old People.

PORTER, K. R. D. (1962): Ward Design, Lancet, ii, 35.

U.S. Department OF Health, Education and Welfare (1962): 'Elements of Progressive Patient Care'. Washington.

WARREN, M. (1943): Care of Chronic Sick, Brit. med. $\mathcal{F}$., ii, 822. 